\title{
Decreased type III collagen expression in human uterine cervix of prolapse uteri
}

\author{
MASAAKI IWAHASHI ${ }^{1}$ and YASUTERU MURAGAKI ${ }^{2}$
}

Departments of ${ }^{1}$ Obstetrics and Gynecology, and ${ }^{2}$ Pathology, Wakayama Medical University, Wakayama 641-0012, Japan

Received November 1, 2010; Accepted January 4, 2011

DOI: 10.3892/etm.2011.204

\begin{abstract}
The precise mechanism of prolapse uteri is not fully understood. There is evidence to suggest that abnormalities of collagen, the main component of extracellular matrix, or its repair mechanism, may predispose women to prolapse. To investigate the characteristic structure of human uterine cervix of patients with prolapse uteri, various types of collagen expression in the uterine cervix tissues of the prolapse uteri were compared to those of normal uterine cervix. After informed consent, 36 specimens of uterine cervical tissues were obtained at the time of surgery from 16 postmenopausal women with prolapse uteri (stage III-IV by the Pelvic Organ Prolapse Quantification examination) and 20 postmenopausal women without prolapse uteri (control group). Collagens were extracted from the uterine cervix tissues by salt precipitation methods. The relative levels of various collagens were evaluated by sodium dodecyl sulfate-polyacrylamide gel electrophoresis. The uterine cervix was longer in the patients with prolapse uteri than those of postmenopausal controls without prolapse uteri. The ratios of type III to type I collagen in the uterine cervical tissues were significantly decreased in the prolapse uteri, as compared to those of the postmenopausal uterine cervix without prolapse. These results suggest that decreased type III collagen expression may play an important role in determing the physiology and structure of the uterine cervix tissues of prolapse uteri.
\end{abstract}

\section{Introduction}

The extracellular matrix (ECM) is considered to play an important role in the stability of tissues and in regulating the growth and differentiation of cells $(1,2)$. Synthesis, accumulation and catabolism of the ECM occur during wound healing and during the initiation and progression of numerous diseases (3).

Moreover, it is generally acknowledged that the ECM does not function as a mere passive scaffold for connective tissue

Correspondence to: Dr Masaaki Iwahashi, Department of Obstetrics and Gynecology, Wakayama Medical University, 811-1 Kimiidera, Wakayama 641-0012, Japan

E-mail:masaaki@wakayama-med.ac.jp

Key words: collagen, cervix, uterine prolapse within organ architecture. It also plays an 'informational' role through a network of interactions between cells and signal molecules which is of primary importance in the control of cellular proliferation and motility during histogenesis for the maintenance of tissue homeostasis and in cancer development.

Prolapse of the pelvic organs is a common disease affecting the lives of millions of women. Women with prolapse suffer from chronic pelvic pain and pressure, urinary and fecal incontinence, sexual dysfunction and social isolation. Despite the high prevalence of this disease and the devastating impact on the lives of women, very little is known about its pathophysiology.

Recently, it has been suggested that a structural defect in the vagina and its supportive tissues, such as a decrease in collagen content or a change in collagen subtypes, is one of the mechanisms that predisposes a woman to prolapse. Thus, there have been many studies throughout the literature in which collagen is analyzed in vaginal and uterine-supporting ligament biopsies procured at the time of a repair of prolapse in patients with prolapse or at the time of a hysterectomy in patients without prolapse. The comparison of these samples has provided conflicting results (4-13).

Trauma or pathology may lead to altered responses to mechanical stresses placed on connective tissue, producing changes in the ECM. Alterations in collagen synthesis and collagen types are causally related to connective tissue disorders, such as inguinal hernia (14), genito-urinary prolapse and urinary stress incontinence $(15,16)$. The uterine cervices of patients with prolapse are dramatically altered when compared to those without prolapse. Therefore, the precise control of ECM metabolism in the uterine cervix is critical for the pathophysiology of prolapse uteri.

In the present study, we investigated the composition of the various types of collagen, the major component of ECM, in human uterine cervical tissues of prolapse uteri by sodium dodecyl sulfate-polyacrylamide gel electrophoresis (SDS-PAGE).

\section{Materials and methods}

This project was approved by the Committee on Investigations Involving Human Subjects of Wakayama Medical College. Informed consent was obtained from each subject after the purpose and nature of the study had been fully explained. 
Table I. Relative abundance of the $\alpha 1$ (III) and $\alpha 1(\mathrm{~V})$ chains of collagen as compared to the $\alpha 1(\mathrm{I})$ chain in the human uterine cervix tissues of the postmenopausal uterus as control and the prolapse uteri.

\begin{tabular}{|c|c|c|c|c|}
\hline & \multirow[t]{2}{*}{ No. of patients } & \multirow[t]{2}{*}{ Cervical length (mm) } & \multicolumn{2}{|c|}{ Relative ratio of collagen $\alpha$ chain } \\
\hline & & & $\alpha 1(\mathrm{III}) / \alpha 1(\mathrm{I})$ & $\alpha 1(\mathrm{~V}) / \alpha 1(\mathrm{I})$ \\
\hline Control & 16 & $28 \pm 5$ & $0.18 \pm 0.05$ & $0.02 \pm 0.01$ \\
\hline Prolapse uteri & 20 & $37 \pm 8^{a}$ & $0.06 \pm 0.03^{\mathrm{b}}$ & $0.01 \pm 0.01$ \\
\hline
\end{tabular}

Data are presented as the means $\pm \mathrm{SEM} .{ }^{\mathrm{a}} \mathrm{P}<0.05 ;{ }^{\mathrm{b}} \mathrm{P}<0.01$.

Patients and tissues. Sixteen uterine cervical samples were obtained from postmenopausal Japanese women (59-85 years of age) with uterine prolapse, who had undergone a vaginal hysterectomy and colpoperineoplasty, and were defined as the prolapse group. A Pelvic Organ Prolapse Quantification examination (17) was performed on the patients with uterine prolapse to define the stage of prolapse. All patients with uterine prolapse showed stage II or greater prolapse (POP-Q).

As the control group, 20 uterine cervical samples were obtained from postmenopausal Japanese women (58-82 years of age) without uterine prolapse, who had undergone a abdominal hysterectomy for a benign indication other than prolapse. Variables, including age, postmenopausal period, parity and BMI, were not significantly different in the two groups. None of the patients received any hormone therapy before surgery.

The uterine cervical length was measured from the internal to external os along the cervical canal, and values are expressed in millimeters.

SDS-PAGE of pepsin-solubilized collagens from the uterine cervical tissues. Minced samples of human uterine cervical tissues were washed overnight in cold distilled water and freed of blood. Tissues were homogenized with a Polytron homogenizer in 50 volumes of $0.5 \mathrm{M}$ acetic acid that contained $1 \mathrm{mg} / \mathrm{ml}$ pepsin (Sigma Chemical Co., St. Louis, MO, USA). Collagens were extracted with constant stirring for $24 \mathrm{~h}$ at $4^{\circ} \mathrm{C}$. Each solution was centrifuged at $39,000 \times \mathrm{g}$ for $1 \mathrm{~h}$ at $4^{\circ} \mathrm{C}$. Collagens were reextracted from the pellet under the same conditions as described above for $48 \mathrm{~h}$.

The supernatants corresponding to individual samples were then combined, and collagens were precipitated by addition of $4.0 \mathrm{M} \mathrm{NaCl}$ to a final concentration of $2.0 \mathrm{M}$. Each precipitate was dissolved in $0.5 \mathrm{M}$ acetic acid, and the solution was dialyzed against $0.02 \mathrm{M} \mathrm{Na}_{2} \mathrm{HPO}_{4}$. Precipitated collagens were redissolved in $0.5 \mathrm{M}$ acetic acid, dialyzed exhaustively against $0.05 \mathrm{M}$ acetic acid and finally lyophilized.

The solubility of the tissue collagen from each uterine cervical tissue sample was estimated by comparing the hydroxyproline content of the initial homogenate to that of the final solution of collagen (18). Type V collagen was isolated by salt precipitation from pepsin digests of human uterine cervical tissues by the methods described elsewhere $(19,20)$. The extracted type V collagen was also lyophilized.

Estimation of the relative abundance of the $\alpha 1$ (III) chain and $\alpha 1(\mathrm{~V})$ chain was performed by interrupted gel electrophoresis

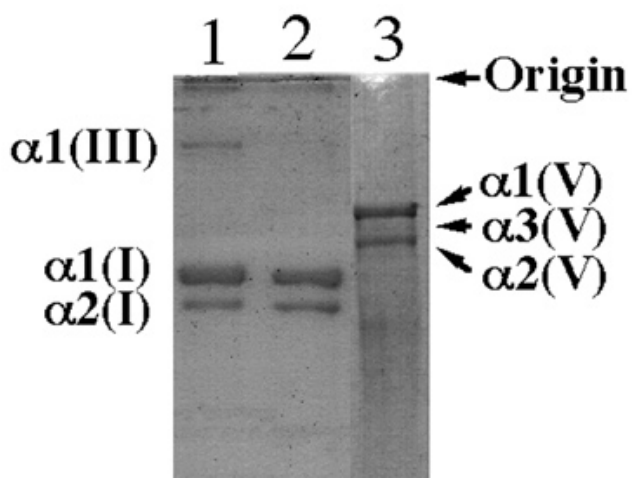

Figure 1. SDS-PAGE of pepsin-solubilized collagens from the human uterine cervical tissues. Normal postmenopausal uterine cervical tissues (lane 1), uterine cervical tissues with prolapse uteri (lane 2) and type V collagen extracted from the human uterine cervical tissues (lane 3). Samples of heat-denatured collagen (5 $\mu \mathrm{g}$, lanes 1 and $2 ; 1.0 \mu \mathrm{g}$, lane 3 ) were subjected to electrophoresis on a slab gel for $1 \mathrm{~h}$. After reduction in situ with $\beta$-mercaptoethanol for $30 \mathrm{~min}$, electrophoresis was resumed for $1 \mathrm{~h}$.

(21). Electrophoresis was performed in an $8 \%$ polyacrylamide slab gel (Sigma Chemical Co.). The gel and electrode buffers consisted of $0.1 \mathrm{M}$ phosphate buffer, $\mathrm{pH} 7.2$, containing $0.1 \%$ SDS (Nacalai Tesque, Inc., Kyoto, Japan), as previously described (22). Lyophilized samples of collagen and type $\mathrm{V}$ collagen were dissolved at a concentration of $0.2 \mathrm{mg} / \mathrm{ml}$ and denatured by heating in the gel buffer that contained $1 \%$ SDS at $60^{\circ} \mathrm{C}$ for $30 \mathrm{~min}$.

Aliquots of $25 \mu \mathrm{l}$ of each solution of denatured collagens and $5 \mu \mathrm{l}$ of denatured type $\mathrm{V}$ collagen were applied to the gel and subjected to electrophoresis at $80 \mathrm{~mA}$. After $1.5 \mathrm{~h}$, the current was switched off and sample wells were filled with a solution of $20 \% \beta$-mercaptoethanol (Wako Chemical Co., Osaka, Japan) in gel buffer, and the $\beta$-mercaptoethanol was allowed to diffuse into the gel for $1 \mathrm{~h}$ to cleave the intramolecular disulfide bonds of type III collagen, [ $\alpha 1($ III) $] 3$. Then, electrophoresis was resumed and allowed to continue for another $1 \mathrm{~h}$. Each collagen $\alpha$ chain was stained with Coomassie brilliant blue (Sigma Chemical Co.) and quantitated by densitometry.

The relative amounts of $\alpha 1(\mathrm{III})$ or $\alpha 1(\mathrm{~V})$ chains were calculated by dividing the intensities of the band areas under densitometric peaks of $\alpha 1$ (III) and of $\alpha 1(\mathrm{~V})$ by that of $\alpha 1(\mathrm{I})$. In this method, the $\alpha$ chains derived from type IV collagen could not be evaluated because of degradation of this collagen by pepsin. 
Statistical analysis. The uterine cervical length was expressed as the mean \pm SD. Densitometric data were expressed as the mean \pm SEM. Mean values were compared by the Student's t-test or analysis of variance using a StatView software program on a Macintosh computer. Two-tailed P-values $<0.05$ were considered statistically significant.

\section{Results}

The uterine cervix of prolapse uteri were significantly longer compared to those of the postmenopausal uterus (Table I).

Although the relative levels of $\alpha 1(\mathrm{I})$ and $\alpha 1(\mathrm{~V})$ were similar in the uterine cervical tissues in the two groups (Fig. 1), those of $\alpha 1$ (III) were decreased in the uterine cervical tissues of the prolapse uteri compared to those of the normal postmenopausal uterine cervix (Fig. 1). The mean ratio of the intensity of the band of $\alpha 1$ (III) to that of $\alpha 1$ (I) in the uterine cervix tissues of prolapse uteri was significantly lower than that in the normal postmenopausal uterine tissues $(\mathrm{P}<0.01)$. The data are summarized in Table I.

\section{Discussion}

In the present study, we investigated changes in the composition of the ECM, including type I, III and V collagens, in the human uterine cervical tissues obtained from the women with or without uterine prolapse. We were able to solubilize $70-85 \%$ of collagen in the human cervical tissues, as measured by reference to levels of hydroxyproline (data not shown). Therefore, it was postulated that the extracted collagen may accurately reflect the entire complement of collagen in the tissues.

Human cervix is made up mainly of fibrous connective tissues in which collagen (23) and glycosaminoglycans (24) predominate. The physiological properties of the cervix depend on the interplay between collagen and glycosaminoglycan molecules (25). Therefore, collagen may play a pivotal role in the structure and function of human uterine cervix.

Although type I and type III collagens are commonly found in combination, the ratios of type III to type I collagen in the tissues of human cervix of the patients with uterine prolapse were significantly lower than those of the patients without prolapse. Our findings suggest at least two possible mechanisms for decreased type III collagen expression in the uterine cervices with uterine prolapse. First, the reduced type III collagen expression in the pelvic organ supporting system involving uterine cervix may induce genital prolapse. However, these present findings conflict with those of previous reports (4-13).

Second, the pelvic supporting system is relaxed in patients with uterine prolapse. Therefore, a progressively increasing mechanical load may reduce focal type III collagen expression in uterine cervical tissues.

It has been suggested that the ECM in human cervical tissues may be controlled by collagenases, hormones, such as estrogens (26-28), dehydroepiandrosterone (29) and prostaglandins $(30,31)$, and/or cytokines, such as IL-I (32) and IL-8 (33-37).

Recent studies have shown that nitric oxide (NO) may participate in the biochemical and anatomical changes in human and animal cervical tissues (38-42). In addition, it has been suggested that NO directly controls various metalloproteinases (43). A low estrogen level is commonly recognized in postmenopausal women with or without uterine prolapse. Therefore, in regards to the causes of uterine prolapse, we may suggest not only lack of estrogen, but also other factors, such as NO.

The ECM of the uterine cervix is a fiber-reinforced compositive viscoelastic material made up of fibrillar collagen (two thirds type I, one third type III) and proteoglycans (hyaluronic acid, chondroitin sulfate, keratan sulfate and dermatan sulfate) $(44,45)$. Thus, our study suggests that a decreased ratio of type III collagen and an increased ratio of type I collagen in the uterine cervix may induce elongation of the cervix in terms of uterine prolapse. Type III collagen belongs to a family of fibril-forming collagens that are found throughout the body. Each of the fibrillar collagens has a unique structural profile that in turn imparts tissues with distinct physical properties $(46,47)$. This collagen, forming smaller fibers, predominates in tissues that require increased flexibility and distensibility and are subject to periodic stress, such as the vasculature. Therefore, decreased expression of type III collagen, the main macromolecular component of the ECM of the cervix, may be a key event in the development of uterine prolapse.

In conclusion, these changes in the composition of collagens may result in the morphologic and functional characteristics of human uterine cervix with uterine prolapse.

This study furthers the understanding of the pathophysiology of human uterine cervix in terms of ECM metabolism. Further research is required to elucidate the mechanisms regulating the expression of genes of other types of collagen or metalloproteinases in the uterine cervix during the premenopausal period and pathological status.

\section{References}

1. Lin CQ and Bissell MJ: Multi-faceted regulation of cell differentiation by extracellular matrix. FASEB J 7: 737-743, 1993.

2. Madri JA and Basson MD: Extracellular matrix-cell interactions: dynamic modulators of cell, tissue and organism structure and function. Lab Invest 66: 519-521, 1992.

3. Haralson MA: Extracellular matrix and growth factors: an integrated interplay controlling tissue repair and progression to disease. Lab Invest 69: 369-372, 1993.

4. Goepel C, Heller L, Methfessel HD and Koelbl H: Periurethral connective tissue stastus of postmenopausal women with genital prolapse with and without stress incontinence. Acta Obstet Gynecol Scand 82: 659-664, 2003.

5. Soderberg MW, Falconer C, Bystrom B, Malmstrom A and Ekman G: Young women with genital prolapse have a low collagen concentration. Acta Obstet Gynecol Scand 83: 1193-1198, 2004.

6. Jackson SR, Avery NC, Tarlton JF, Eckford SD, Abrams P and Bailey AJ: Changes in the metabolism of collagen in genitourinary prolapse. Lancet 347: 1658-1661, 1996.

7. Liapis A, Bakas P, Pafiti A, Frangos-Plemenos M, Arnoyannaki N and Creatsas G: Changes of collagen type III in female patients with genuine stress incontinence and pelvic floor prolapse. Eur J Obstet Gynecol Reprod Biol 97: 76-79, 2001.

8. Makinen J, Kahari VM, Soderstrom KO, Vuorio E and Hirvonen T: Collagen synthesis in the vaginal connective tissue of patients with and without uterine prolapse. Eur J Obstet Gynecol Reprod Biol 24: 319-325, 1987.

9. Kokcu A, Yanik F, Cetinkaya M, Alper T, Kandemir B and Malatyalioglu E: Histopathological evaluation of the connective tissue of the vaginal fascia and the uterine ligaments in women with and without pelvic relaxation. Arch Gynecol Obstet 226: 75-78, 2002. 
10. Chen BH, Wen Y, Li H and Polan ML: Collagen metabolism and turnover in women with stress urinary incontinence and pelvic prolapse. Int Urogynecol J Pelvic Floor Dysfunct 13: 80-87, 2002.

11. Takano CC, Girao MJ, Sartori MG, et al: Analysis of collagen in parametrium and vaginal apex of women with and without uterine prolapase. Int Urogynecol J Floor Dysfunct 13: 342-345, 2002.

12. Ewies A, Al-Azzawi F and Thompson J: Changes in extracellular matrix proteins in the cardinal ligaments of post-menopausal women with or without prolapse: a computerized immunohistomorphometric analysis. Hum Reprod 18: 2189-2195, 2003.

13. Moalli PA, Shand SH, Zyczynski HM, Gordy SC and Meyn LA: Remodeling of vaginal connective tissue in patients with prolapse. Obstet Gynecol 106: 953-963, 2005.

14. Friedman D, Boyd C, Norton P and Deak S: Altered type III collagen synthesis in patients with inguinal hernia. Am Surg 218: 754-760, 1993.

15. Ulmsten U, Ekman G, Giertz G and Malmstrom A: Different biochemical composition of connective tissue in continent and stress incontinent women. Acta Obstet Gynecol Scand 66: 455-457, 1987.

16. Versi E, Cardozo L, Bribcat M, Cooper D, Montgomery J and Studd J: Corelation of urethral physiology and skin collagen in postmenopausal women. Br J Obstet Gynecol 95: 147-152, 1988.

17. Bump RC, Mattiasson A, Bo K, et al: The standardization of terminology of female pelvic organ prolapse and pelvic floor dysfunction. Am J Obstet Gynecol 175: 10-17, 1996.

18. Kivirikko KI and Prockop DJ: Hydroxylation of proline in synthetic polypeptides with purified protocollagen hydroxylase. J Biol Chem 242: 4009-4012, 1967.

19. Furuto DK and Miller EJ: Isolation of a unique collagenous fraction from limited pepsin digests of human placental tissue. J Biol Chem 255: 290-295, 1980.

20. Miller EJ and Rhodes RK: Preparation and characterization of the different types of collagen. Methods Enzymol 82: 33-64, 1982.

21. Sykes B, Puddle B, Francis M and Smith R: The estimation of two collagen from human dermis by interrupted gel electrophoresis. Biochem Biophys Res Commun 72: 1472-1480, 1976.

22. Laemmli UK: Cleavage of structural proteins during the assembly of the head of bacteriophage T4. Nature 227: 680-685, 1970.

23. Danforth DN: The fibrous nature of the human cervix, and its relation to isthmic segment in gravid and non gravid uteri. Am J Obstet Gynecol 53: 541-560, 1974.

24 Kitamura K, Ito A, Mori Y and Hirakawa S: Glycosaminoglycans of human uterine cervix: heparan sulfate increase with reference to cervical ripening. Biochem Med 23: 159-167, 1980.

25. Wallis RM and Hiller K: Regulation of collagen dissolution in human cervix by oestradiol-17b and progesterone. J Reprod Fertil 62: 55-61, 1981.

26. Sato T, Ito A, Mori Y, Yamashita K, Hayakawa T and Nagase $H$ : Hormonal regulation of collagenolysis in uterine cervical fibroblasts. Modulation of synthesis of procollagenase, prostromelysin and tissue inhibitor metalloproteinases (TIMP) by progesterone and oestradiol 17 b. Biochem J 275: 645-650, 1991.

27. Rajabi MR, Dodge GR, Solomon S and Poole AR: Immunochemical and immunohistochemical evidence of estrogen-mediated collagenolysis as a mechanism of cervical dilatation in the guinea pig at partrition. Endocrinology 128: 371-378, 1991

28. Mochizuki M, Honda T, Deguchi M, Morikawa H and Tojo S: A study of the effect of dehydroepiandrosterone sulfate on so-called cervical ripening. Acta Obstet Gynecol Scand 57: 397-401, 1978.
29. Uldbjerg N, Forman A, Petersen L, et al: Biochemical changes of the uterus and cervix during pregnancy. In: Medicine of the Fetus and Mother. Reece EA, Hobbins JC, Mahoney MJ and Petrie RH (eds). JB Lippincott Co., Philadelphia, pp849-868, 1992.

30. Kelly RW: Pregnancy maintenance and partrition: the role of prostaglandin in manipulating the immune and inflammatory response. Endocr Rev 15: 684-706, 1994.

31. El Maradney E, Kanayama N, Halim A, Maehara K, Sumimoto K and Terao T: The effect of interleukin-1 in rabbit cervical ripening. Eur J Obstet Gynecol Reprod Biol 60: 75-80, 1995.

32. Barclay CG, Brennad JE, Kelly RW and Calder AA: Interleukin-8 production by human cervix. Am J Obstet Gynecol 169: 625-632, 1993.

33. El Maradney E, Kanayama N, Kobayashi H, et al: The role of hyaluronic acid as a mediator and regulator of cervical ripening. Hum Reprod 12: 1080-1088, 1997.

34. Osmers R, Blaser J, Kuhn W and Tshesche H: Interleukin-8 synthesis and the onset of labor. Obstet Gynecol 86: 223-229, 1995.

35. Chwalisz K, Benson M, Scholz P, Daum J, Beier HM and Hegele-Hartung C: Cervical ripening with cytokine interleukin-8, interleukin-1 beta and tumour necrosis factor alpha in guinea-pigs. Hum Reprod 9: 2173-2181, 1994.

36. El Maradney E, Kanayama N, Halim A, Maehara K, Sumimoto K and Terao T: Interleukin-8 induces cervical ripening in rabbits. Am J Obstet Gynecol 171: 77-83, 1994.

37. Garfield RE, Saade G, Buhimschi C, et al: Control and assessment of the uterus and cervix during pregnancy and labour. Hum Reprod Update 4: 673-695, 1998.

38. Tschugguel W, Schneeberger C, Lass H, et al: Human cervical ripening is associated with an increase in cervical inducible nitric oxide synthase expression. Biol Reprod 60: 1367-1372, 1999.

39. Buhimschi I, Ali M, Jain V, Chwalisz $\mathrm{K}$ and Garfield RE: Differential regulation of nitric oxide in the rat uterus and cervix during pregnancy and labour. Hum Reprod 11: 1755-1766, 1996.

40. Chwalisz K, Shao-Qing S, Garfield RE and Beier HM: Cervical ripening in guinea pigs after a local application of nitric oxide. Hum Reprod 12: 2093-2101, 1997.

41. Ali M, Buhimschi I, Chwalisz K and Garfield RE: Changes in expression of the nitric oxide synthase isoforms in rat uterus and cervix during pregnancy and parturition. Mol Hum Reprod 3: 995-1003, 1997.

42. Thomson AJ, Lunan CB, Cameron AD, Cameron IT, Greer IA and Norman JE: Nitric oxide donors induce ripening of the human uterine cervix: a randomised controlled trial. Br J Obstet Gynaecol 104: 1054-1057, 1997.

43. Drapier JC and Bouton C: Modulation by nitric oxide of metalloproteinase regulatory activities. Bioessays 18: 549-556, 1996.

44. Aspeden RM: Collagen organization in the cervix and its relation to mechanical functions. Collagen Relat Res 8: 103-112, 1988.

45. Kleissel HP, van der Rest M, Naftolin F, Glorieux FH and de Leon A: Collagen changes in the human uterine cervix at partruition. Am J Obstet Gynecol 130: 748-753, 1978.

46. Ottani V, Martini D, Franchi M, Ruggeri A and Raspanti M: Hierarchical structures in fibrillar collagen. Micron 33: 587-596, 2002.

47. Oxlund H: Relationships between the biomechanical properties, composition and molecular structure of connective tissues. Connect Tissue Res 15: 65-72, 1986. 